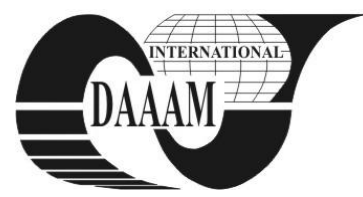

Annals of DAAAM for 2011 \& Proceedings of the 22nd International DAAAM Symposium, Volume 22, No. 1, ISSN 1726-9679 ISBN 978-3-901509-83-4, Editor B. Katalinic, Published by DAAAM International, Vienna, Austria, EU, 2011 Make Harmony between Technology and Nature, and Your Mind will Fly Free as a Bird Annals \& Proceedings of DAAAM International 2011

\title{
COMPLEX EVALUATION OF INVESTMENT EFFICIENCY
}

\author{
CHATRNUCHOVA, L[ucia]; ONDRUSKOVA, O[tilia] \& SABLIK, J[ozef]
}

\begin{abstract}
The importance of the investments results from the role they play in the process of an adaptation of the company and in increasing its competitiveness. The major principle of an evaluation of the investment is a complex assessment of the effectiveness of the investment, i.e. assessment from the point of view of economical, ecological, as well as social effectiveness. The main target of this article is to explain the concept of innovation, investment, efficiency, social efficiency and the necessity to pay the attention to the social efficiency.
\end{abstract}

Key words: investment expertise, investment development, investments efficiency

\section{INTRODUCTION}

Nowadays, the objective of each company should be to increase its own market value with regard to ensure its subsistence needs and to generate profit from its entrepreneurial activity. But it is extremely difficult in the environment characterized by an intense competition and constant changes on the market. But despite that companies that care about their future prosperity must take such measures that help them to handle obstacles better and respond to changes on the market and market needs in time. One of the ways to ensure future prosperity and development of the company is an effective allocation of financial resources into property. To make the investment of often scarce resources effective and efficient, it is necessary for the company to analyze investment and assess its effectiveness. The key role in investment decisions is played by the assessment of effects (economical, environmental, as well as social) resulting from made capital expenditures.

\section{INVESTMENT DEVELOPMENT IN SLOVAKIA}

Investment development of the company is the most important activity of the business management. It contributes to the economical and social development and influences the environment management. The appreciation of the contributed capital is a driving engine (motivation) of the investment development. An effective investment development constitutes a guarantee of prosperity of an enterprise for the future.

It is very important for companies to find appropriate means to keep the company in the market mechanism and to build trust with customers. If the company wants to maintain competitiveness, it must follow the way of innovations. Each company must find its own successful strategic way how to manage and sell innovations. Innovations constitute the main area for a sustainable growth and progress and at the same time create a considerable competitive advantage. Investments into education, innovations, research and development increase the company value and expand the horizon of new possibilities and market opportunities. Based on our research the innovative development in the companies operating on the Slovak market is focused mainly on: see figure 1

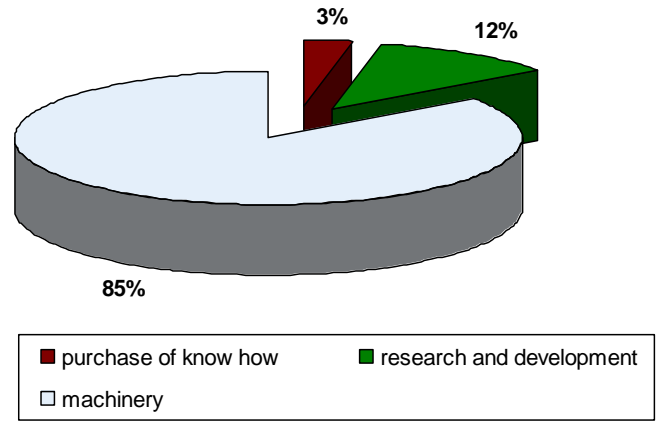

Fig. 1. Innovative development in Slovak companies

\section{THE METHODOLOGY OF THE EVALUATION OF A COMPLEX EFFECTIVENESS OF THE INVESTMENT}

The contemporary literature provides a complex methodology of the evaluation of the effectiveness of the investment. Complexity consists in the evaluation of the investment from the economical, environmental and social point of view. Based on our research this methodology is useless for practice because of its incomplete processing from the point of view of the social effectiveness, inconsistent input data, inconsistent evaluation of the investments, different presentations of the issues, and the change of conditions on the Slovak market. Currently, application and implementation of the evaluation of the complex effectiveness of the investment in Slovakia is not obvious. Mostly, this methodology (although incomplete) is applied in the companies with foreign equity participation.

Therefore, it is necessary to:

- prepare the new methodology for the complex investment evaluation

- integrate procedure and input data for the calculation of economical, environmental and social effectiveness

- respect (new) legislative regulations to protect workers (directives, EU laws).

\subsection{The effectiveness of the investment}

There are several definitions of the term „effectiveness“. All of them deal with the redistribution of resources in order to meet required outputs. The effectiveness of the investments can be defined as the rate of appreciation of the invested capital (incurred costs). It is possible to express the effectiveness of the investment mathematically as the ratio between the value of the effective output and the value of the input necessary for achieving the effective output during the lifetime of investment. The quantification of the complex effectiveness of the investment:

$$
E=\frac{\text { output }}{\text { input }}=\frac{\text { effects }}{V_{k}}=\frac{E_{E}+E_{E N V}+E_{S O C}}{V_{k}}
$$


Where:

$\mathrm{E}$ - complex effectiveness of the investment

$\mathrm{E}_{\mathrm{E}}-$ economical effectiveness

$\mathrm{E}_{\mathrm{EN}}-$ environmental effectiveness

$\mathrm{E}_{\mathrm{SOC}}-$ social effectiveness

$\mathrm{V}_{\mathrm{k}}$ - paid-in capital

The basic principle of the expertise of the investment is its complex assessment, see figure 2:

\begin{tabular}{|ll|}
\hline Effectiveness & Effects \\
\hline Economical & $\begin{array}{l}\text { profit, costs, rentability, liquidity, } \\
\text { development }\end{array}$ \\
\hline environmental & $\begin{array}{l}\text { material saving, energy saving, } \\
\text { minimalization and recycling of the } \\
\text { waste, saving of payments and fines } \\
\text { for environmental damage }\end{array}$ \\
\hline Social & $\begin{array}{l}\text { creation of new jobs, improvement of } \\
\text { working conditions, safety and health } \\
\text { protection, work injuries, work culture }\end{array}$ \\
\hline
\end{tabular}

Fig. 2. Complex assessment of the investment

\subsection{Defining social effectiveness}

Social effects represent social contributions for subjects' involved (state, municipality, company, and employee). A company in its actions carries out measurements resulting from legal regulations and norms. The fact that the enterprise evaluates investments also from the point of view of social effects is an expression of its business ethics and adopted ethics code. The company through social effectiveness contributes to the creation of positive social-psychological environment (beyond legal obligations).

$\begin{array}{ll}\text { Company } & \text { Employee } \\ \text { - creation of job } & \text { - employee's needs (wages, } \\ \text { opportunities } & \text { education, insurance, } \\ \text { - loss reduction as a result } & \text { working conditions) } \\ \text { of fluctuation } & \text { - stability of jobs } \\ \text { - cost reduction from } & \text { - improvement of working } \\ \text { sickness absence } & \text { environment } \\ \text { - loss reduction from } & \text { - increase in work culture } \\ \text { injuries } & \\ \text { - reduction of faulty pieces } & \\ & \\ & \text { Social effects }\end{array}$

Fig. 3. Social effects

\subsection{Quantification of social effects}

The quantification of social effects is problematic. Current methodology of the evaluation of the social effectiveness suggests the evaluation of the most important social effectcreation of a new job. The effort is to enable the expression of the range of social effects through converter (equivalent) to economic benefits:

$$
E_{S O C}=u . e[\text { monetary units] }
$$

Where:

$\mathrm{u}-$ the range of social effect of the investment [E.g. the number of jobs created]

$\mathrm{e}$ - economic converter - economic benefit (effect) per unit of the range of the social effect of the investment [e.g. $€ / 1$ job]

$\mathrm{E}_{\mathrm{SOC}}-$ index of social effectiveness $[€]$

Subsequently, we can express socio - economic effectiveness of the investment:
Where:

$$
\mathrm{R}_{\mathrm{se}}=\frac{\sum_{\mathrm{i}=1}^{\mathrm{n}}\left(\mathrm{E}_{\mathrm{ei}}+\mathrm{E}_{\mathrm{soci}}\right)}{\sum_{\mathrm{i}=1}^{\mathrm{n}} \mathrm{V}_{\mathrm{ki}}}
$$

$E_{e i}-$ average economic effects of the investment in i-th scope of evaluation

$E_{\text {soc } i}-$ average social effects in i-th scope of evaluation

$\mathrm{V}_{\mathrm{ki}}$ - the value of paid-in capital in i-th scope of evaluation

$$
\mathrm{i}=1 \div \mathrm{n}
$$

3.4 Model of the evaluation of the social effect of the investment

$\mathrm{E}_{\mathrm{SOC}}=\mathrm{u} \cdot \mathrm{e}=\mathrm{P}_{\mathrm{pm}} \cdot \mathrm{p}_{\mathrm{pm}}$

$\mathrm{E}_{\mathrm{SOC}}=$ number of new jobs created $*$ economic benefit of a 1 new job

Where:

$\mathrm{P}_{\mathrm{pm}}-$ given by the project IZ

$\mathrm{p}_{\mathrm{pm}}$ - the resulting benefits from 1 new job created, it represents the amount of savings on the level of (scope of evaluation):

- state - reduction of benefits, payroll levies, costs for staff retraining

- enterprise (ent) - profit, social fund

- employee (emp) - carrying out of needs

In consequence to it:

$$
E_{S O C}=\frac{\sum_{i=1}^{n} E_{S O C i}}{V_{k i}}=\frac{E_{S O C_{-} s t a t e}}{V_{k_{-} \text {state }}}+\frac{E_{\text {SOC_ent }}}{V_{k_{-} e n t}}+\frac{E_{S O C_{-} e m p l}}{V_{k_{-} e m p}}
$$

\section{CONCLUSION}

The investment decisions represent a very important process enabling a company to carry out its strategic objectives. The importance of the investments result from the role they play in the process of the adaptation of an enterprise and increasing of its competitiveness. The investment decision is considered to be one of the most important decisions, as it directly determines the future of the company. It is a decision characterized by long-tem duration, difficulties with revisions of the decisions, necessity to take into account the factors of time and risk, while respecting consistently basic strategic objective of the company. The key role in investment decision is played by the evaluation of the effects (economical, environmental, as well as social) resulting from made capital expenditures. The evaluation of social effectiveness will help to achieve ecological, economical and social harmonization of the company.

\section{REFERENCES}

Janeková, J., Kádárová, J. (2010). Management of investment development of the company, The Faculty of Mechanical Engineering, ISBN 978-80-553-0429-8, Košice

Sablik, J. (2010). Management of investment development of the company, non - publicated materials. Slovak University of Technology, Trnava, 2010

Sakál, P. and authors's team (2007). Strategic management in manager's practic. SP SYNERGIA, ISBN 978-80-8929104-5, Trnava

Chatrnúchová, L., Ondrušková, O., Sablik, J. (2010). Methods for social efficiency evaluation of the investment, Proceedings of InvEnt 2010, Žilina, ISBN 978-80-8940112-3. pp.. 164--167. University of Žilina, Žilina

Szabó, P., Chatrnúchová, L., Sablik, J., Vičíková, J. (2010). Investment decisions in conditions of continual change. Proceedings of MMK 2010, 2010. Hradec Králové. ISBN 978-80-86703-41-1. pp. 926--930. Magnanimitas, Hradec Králové 